\title{
Frequency of retinopathy of prematurity at a tertiary referral center
}

\author{
Niusha Kasiri ${ }^{1}$, Ali Kasiri ${ }^{2}$, Fereydoun Farrahi ${ }^{2}$, Mohammad Sadegh Mirdehghan ${ }^{2}$ and Rozhin Kasiri ${ }^{1}$ \\ ${ }^{1}$ School of Medicine, Ahvaz Jundishapur University of Medical Sciences, Ahvaz, Iran \\ ${ }^{2}$ Infectious Ophthalmologic Research Center, Faculty of Medicine, Ahvaz Jundishapur University of Medical Sciences, Ahvaz, Iran
}

\begin{abstract}
Background: With advances in medical facilities and increased survival of premature infants, the prevalence of retinopathy of prematurity (ROP) has increased. This study aimed to determine the frequency of ROP and its associated risk factors.

Methods: This descriptive-analytical, retrospective study included all premature infants with a birth weight $(\mathrm{BW}) \leq 2,500 \mathrm{~g}$ and/or gestational age $(\mathrm{GA}) \leq 35$ weeks who were referred to Imam Khomeini Hospital in Ahvaz, Iran, for ROP screening over a 7-year period from April 2013 to April 2020. Demographic criteria, associated risk factors, and findings of eye examinations were collected and analyzed.

Results: Of the 812 at-risk infants screened, 807 met the inclusion criteria. ROP was observed in $316(39.0 \%)$ of the 807 premature infants, with types I and II in $142(45.0 \%)$ and $174(55.0 \%)$ infants, respectively. The mean GA $(29.6 \pm 2.5$ weeks versus $30.7 \pm 2.5$ weeks $)$ and BW $(1,203.6 \pm 382.8 \mathrm{~g}$ versus $1,333.5 \pm 386.5 \mathrm{~g})$ were significantly lower in infants with ROP than in those without ROP (both $P<0.001)$. GA $(\mathrm{r}=0.80$; $P<0.001)$ and $\mathrm{BW}(\mathrm{r}=0.85 ; P<0.001)$ had a strong positive correlation with ROP, and the correlation increased as GA and BW decreased (all $P<0.001)$. Associated risk factors in infants with ROP, in order of frequency, were oxygen therapy $(22.8 \%)$, respiratory distress $(16.1 \%)$, phototherapy (14.6\%), blood transfusion (5.7\%), apnea (4.1\%), mechanical ventilation (1.6\%), and intraventricular hemorrhage (0.9\%). Multivariate regression analyses showed low GA and BW (both $P<0.05$ ) as independent predictors of ROP. Conclusions: The frequency of ROP in premature infants was slightly higher than the average range reported for domestic and foreign statistics. Low BW and GA were independent predictors of ROP.
\end{abstract}

\section{KEYWORDS}

low birth weight, premature infant, retinopathy of prematurity, frequency, risk factors, oxygen therapy, respiratory distress, phototherapy, blood transfusion, apnea, mechanical ventilation, intraventricular hemorrhage

\section{INTRODUCTION}

Retinopathy of prematurity (ROP), formerly known as "retrolental fibroplasia," is a retinal disease of infants [1]. It is a preventable cause of blindness in children. In premature infants, retinal vascular completion occurs in the extrauterine environment. Numerous factors can disrupt the process of vascular development or "neovascularization," which leads to ROP in infants [2]. Gestational age (GA) and birth weight (BW) are major risk factors for ROP, with other factors being less significantly associated with ROP [3].

Correspondence: Niusha Kasiri, School of Medicine, Ahvaz Jundishapur University of Medical Sciences, Ahvaz, Iran. E-mail: niusha_k10@yahoo.com. ORCID iD: https://orcid.org/0000-0002-7926-6199

How to cite this article: Kasiri N, Kasiri A, Farrahi F, Mirdehghan MS, Kasiri R. Frequency of retinopathy of prematurity at a tertiary referral center. Med Hypothesis Discov Innov Ophthalmol. 2021 Winter; 10(4): 179-184. https://doi.org/10.51329/mehdiophthal1436

Received: 23 September 2021; Accepted: 09 November 2021

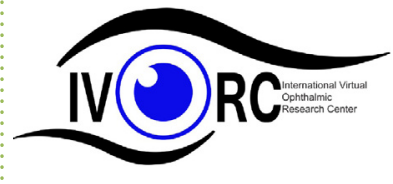

Copyright (C) Author(s). This is an open-access article distributed under the terms of the Creative Commons Attribution-NonCommercial 4.0 International License (http://creativecommons.org/licenses/by-nc/4.0/) which permits copy and redistribute the material just in noncommercial usages, provided the original work is properly cited. (c) (i) (s) 
In the last decade, the prevalence of ROP-related blindness has increased, particularly in developing countries. ROP is the main cause of blindness in China, east and southern Asia, eastern Europe, Latin America, and middle-income countries [4].

The prevalence of ROP in different parts of Iran varies from 5.6\% to 70\% [5-8]. ROP remains a major risk factor for blindness worldwide. Premature infants face a lifelong risk of visual disabilities and ophthalmic complications. Therefore, to reduce the overall rate of complications, lifelong ophthalmology follow-ups should be advised to parents and guardians [9].

ROP affects the retinal arteries in premature infants and can lead to visual impairments ranging from minor defects in visual acuity to retinal detachment and blindness. Risk factors for this disease include preterm delivery, particularly before gestation week 31, and a $\mathrm{BW}<1,500 \mathrm{~g}$. Apnea, maternal problems (diabetes, preeclampsia, and maternal smoking), intraventricular hemorrhage (IVH), respiratory disorders, vitamin $\mathrm{E}$ deficiency, heart disease, elevated blood carbon dioxide, acidosis, hypoxemia, bradycardia, oxygen uptake, increased oxygen consumption, and mechanical ventilation are other causes [10-12].

Other risk factors include respiratory distress syndrome, ethnicity, neonatal infection, and bronchopulmonary dysplasia. Predictors of ROP include underweight and a low intrauterine age [4, 13]. ROP is preventable. Further, if diagnosed early, it can be treated; otherwise, it is progressive and leads to blindness [14].

To our knowledge, the frequency and associated risk factors for ROP in premature infants have not been investigated in Ahvaz, Iran. Therefore, the present study was aimed at determining the frequency of ROP and its associated risk factors in premature infants referred to the Imam Khomeini Hospital in Ahvaz, using a 7-year retrospective sample.

\section{METHODS}

This descriptive-analytical, retrospective study was conducted on premature infants referred to Imam Khomeini Hospital in Ahvaz, Iran, during 2013-2020 for ROP screening. Medical records of all neonates referred from hospitals throughout the Khuzestan province to the Imam Khomeini Referral Hospital in Ahvaz for ROP screening were reviewed. The study received approval from the research committee of Ahvaz Jundishapur University of Medical Sciences (AJUMS) (approval code: IR.AJUMS.HGOLESTAN.REC.1398.028).

Information on GA (based on the first day of the last menstrual period or first-trimester ultrasound and confirmation by physical examination of the infant), pregnancy weight, sex, IVH, in vitro fertilization (IVF), oxygen therapy, respiratory distress, mechanical ventilator, apnea, blood transfusions, and phototherapy were collected from hospital records and via telephone calls to parents if the records were incomplete. Infants with a BW $\leq 2,500 \mathrm{~g}$ and/or $\mathrm{GA} \leq 35$ weeks, who survived until screening, were included. We excluded infants with no documentation of final ROP outcome, loss to follow-up, or death before examination [15]. Infants with life-threatening systemic abnormalities, symptoms of Norrie disease, non-ROP-related media opacities that precluded retinal examination, congenital hydrocephalus, congenital cyanotic heart disease, and referral after 10 weeks post-birth were also excluded.

The first examination of infants with GA $\leq 27$ weeks was conducted at 31 weeks. Infants aged 28-32 weeks were examined at 4-6 weeks post-birth or 31-33 postmenstrual weeks, whichever was later [15]. To achieve a satisfactory pharmacological mydriasis, topical tropicamide 0.5\% (Mydrax; Sina Darou, Tehran, Iran) and phenylephrine 1\% (Sina Darou) eyedrops were administered. All screening and follow-up examinations were performed by two vitreoretinal surgery fellows (A.K. and F.F.) using an indirect ophthalmoscope (Welch Allyn Inc., Skaneateles Falls, NY, USA) with 20- or 30-diopter lenses (VOLK Optical, Mentor, OH, USA). A sterile eyelid speculum and scleral depressor were routinely used.

The ROP classification followed the recommendations outlined by the American Academy of Pediatrics, American Academy of Ophthalmology, and American Association for Pediatric Ophthalmology and Strabismus [16]. Treatment indications were based on the Early Treatment for Retinopathy of Prematurity study [17]. We recorded demographic variables (sex, GA, and BW); use of blood transfusion, oxygen therapy, phototherapy, or mechanical ventilation; occurrence of respiratory distress, apnea, or IVH; and IVF [3].

Collected data were analyzed using IBMSPSS Statistics forWindows, version 22.0 (IBM Corp., Armonk, NY,USA). The data normality assumption was verified using the Kolmogorov-Smirnov test. Quantitative data are expressed as mean and standard deviation, while qualitative data are expressed as number and percentage. The independent $t$-test was used to compare ROP and no-ROP groups. Correlation between ROP and GA or BW was analyzed using Pearson's product-moment correlation statistics. Logistic regression was used to determine independent and significant factors associated with ROP. The level of statistical significance was set at $P<0.05$ for all analyses. 


\section{RESULTS}

The total number of at-risk infants screened was 812 (382 [47.0\%] boys and 430 [52.9\%] girls). Of these, 807 were premature infants with a BW $\leq 2,500 \mathrm{~g}$ and/or GA $\leq 35$ weeks. Among premature infants, $491(61.0 \%) \mathrm{had}$ no ROP, while 316 (39.0\%) had ROP, of whom 142 (45.0\%) had type1 ROP and 174 (55.0\%) had type 2 ROP (Figure 1). The mean GA (29.6 \pm 2.5 weeks versus $30.7 \pm 2.5$ weeks) and BW (1,203.6 \pm 382.8 g versus $1,333.5$ $\pm 386.5 \mathrm{~g}$ ) were significantly lower in the ROP group than in the no-ROP group (both $P<0.001$ ). However, the two groups did not differ $(P=0.243)$ significantly with respect to the sex distribution (ROP group: $154(48.7 \%)$ boys and 162 (51.3\%) girls; no-ROP group: 228 (46.0\%) boys and 268 (54.0\%) girls). We have excluded five infants who failed to have inclusion criteria, yet, all had no-ROP.

Table 1 shows a strong positive correlation between GA and ROP $(\mathrm{r}=0.80 ; P<0.001)$, with a correlation coefficient that increased with reducing GA (all $P<0.001)$. In most infants with ROP $(62.7 \%)$, the GA range was 29-32 weeks (Table 1$)$. Table 2 shows a strong positive correlation between $\mathrm{BW}$ and ROP $(\mathrm{r}=0.85 ; P<0.001)$. The correlation coefficient increased with reduction in BW (all $P<0.001)$. In most infants with ROP $(38.0 \%)$, the BW range was $1,201-1,500 \mathrm{~g}$ (Table 2).

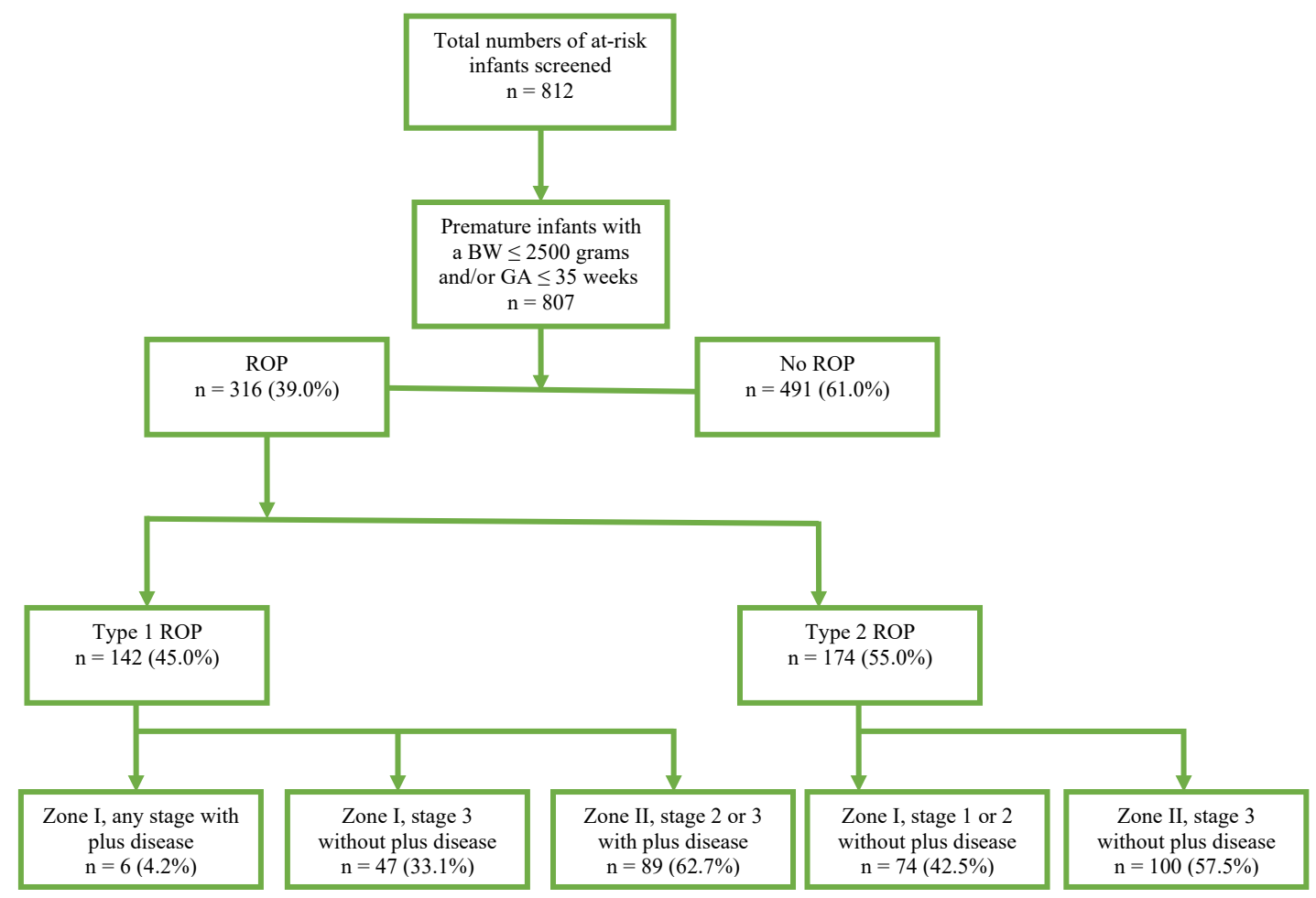

Figure 1. Flowchart of the screened infants referred to the Imam Khomeini Hospital in Ahvaz, Iran, from 2013 to 2020. Abbreviations: BW, birth weight; GA, gestational age; ROP, retinopathy of prematurity; n, number; \%, percentage.

Table 1. Correlation between retinopathy of prematurity and gestational age in premature infants

\begin{tabular}{|c|c|c|c|c|c|c|}
\hline \multirow[t]{2}{*}{ Gestational age } & \multicolumn{2}{|c|}{ Number of screened infants } & \multicolumn{2}{|c|}{ Type of ROP } & \multirow[t]{2}{*}{$P$-value* } & \multirow[t]{2}{*}{$\mathbf{r}$} \\
\hline & Total & ROP & Type I & Type II & & \\
\hline$\leq 28$ weeks, $\mathrm{n}(\%)$ & $206(25.3)$ & $87(27.5)$ & $56(39.4)$ & $31(17.8)$ & $<0.001$ & +0.90 \\
\hline 29-32 weeks, n (\%) & $446(55.0)$ & $198(62.7)$ & $78(55.0)$ & $120(69.0)$ & $<0.001$ & +0.85 \\
\hline $33-35$ weeks, n (\%) & $160(19.7)$ & $31(9.8)$ & $8(5.6)$ & $23(13.2)$ & $<0.001$ & +0.85 \\
\hline Total, n (\%) & $812(100.0)$ & $316(100.0)$ & $142(100.0)$ & $174(100.0)$ & $<0.001$ & +0.80 \\
\hline
\end{tabular}

Abbreviations: ROP, retinopathy of prematurity; w, weeks; n, number; \%, percentage. ${ }^{*}$ Pearson's product-moment correlation.

$P$-values $<0.05$ are shown in bold. 
Table 2. Correlation between retinopathy of prematurity and birth weight in premature infants

\begin{tabular}{|c|c|c|c|c|c|c|}
\hline \multirow[t]{2}{*}{ Birth Weight } & \multicolumn{2}{|c|}{ Number of screened infants } & \multicolumn{2}{|c|}{ Type of ROP } & \multirow[t]{2}{*}{$P$-value } & \multirow[t]{2}{*}{$\mathbf{r}$} \\
\hline & Total & ROP & Type I & Type II & & \\
\hline$\leq \mathbf{1 , 0 0 0}(\mathrm{g}), \mathrm{n}(\%)$ & $148(18.2)$ & $72(22.8)$ & $35(24.6)$ & $37(21.3)$ & $<\mathbf{0 . 0 0 1}$ & +0.95 \\
\hline $1,001-1,200(g), n(\%)$ & $208(25.6)$ & $94(29.7)$ & $44(31.0)$ & $50(28.7)$ & $<0.001$ & +0.90 \\
\hline $1,201-1,500(\mathrm{~g}), \mathrm{n}(\%)$ & $326(40.2)$ & $120(38.0)$ & $50(35.0)$ & $70(40.2)$ & $<0.001$ & +0.90 \\
\hline $1,501-2,000(\mathrm{~g}), \mathrm{n}(\%)$ & $125(15.4)$ & $30(9.5)$ & $13(9.1)$ & $17(9.8)$ & $<0.001$ & +0.70 \\
\hline $2,001-2,500(\mathrm{~g}), \mathrm{n}(\%)$ & $5(0.6)$ & $0(0.0)$ & $0(0.0)$ & $0(0.0)$ & $<0.001$ & +0.50 \\
\hline Total & $812(100.0)$ & $316(100.0)$ & $142(100.0)$ & $174(100.0)$ & $<0.001$ & +0.85 \\
\hline
\end{tabular}

Abbreviations: ROP, retinopathy of prematurity; w, weeks; n, number; $\%$, percentage. ${ }^{*}$ Pearson's product-moment correlation.

$P$-values $<0.05$ are shown in bold.

Risk factors for ROP by frequency of occurrence were oxygen therapy $(\mathrm{n}=72,22.8 \%)$, respiratory distress ( $\mathrm{n}$ $=51,16.1 \%)$, phototherapy $(n=46,14.6 \%)$, blood transfusion $(n=18,5.7 \%)$, apnea $(n=13,4.1 \%)$, mechanical ventilator $(\mathrm{n}=5,1.6 \%)$, and IVH $(\mathrm{n}=3,0.9 \%)$. The multivariate regression analyses showed low GA $(28-32$ weeks, $P=0.027$; $<28$ weeks, $P=0.046)$, and BW $(1,200-1,500 \mathrm{~g}, P=0.011 ; 1,000-1,200 \mathrm{~g}, P=0.039)$ were independent predictors of ROP.

\section{DISCUSSION}

In our study, among 807 included neonates, ROP was detected in 316 premature infants, of whom 142 infants (45.0\%) had type I and 174 (55.0\%) had type II ROP. In infants with ROP, the mean GA was $29.6 \pm 2.5$ weeks, and the mean BW was $1,203.6 \pm 382.8 \mathrm{~g}$, which were significantly lower than in infants with no ROP. GA and BW had strong positive correlations with ROP, and the correlation strengthened as GA and BW reduced. Low GA and BW were independent predictors of ROP.

In a systematic review and meta-analysis, Azami et al. analyzed 42 primary studies from Iran for ROP risk factors, with an overall sample size of 18,000 premature infants [18] and found an estimated prevalence of $23.5 \%$ (95\% confidence interval: 20.4-26.8). Heterogeneity was high (95.6\%) because of differences in geographic regions and provinces or varying inclusion criteria in terms of GA and BW. In addition, diversity in terms of inpatient/outpatient care was an issue. Some studies examined the prevalence of ROP in neonates admitted to the neonatal intensive care unit (NICU), and others included neonates referred to outpatient ophthalmology clinics [18]. Although the rate of ROP showed an increasing trend in Iran over the past two decades, this was not statistically significant [18]. In the present study, the frequency of ROP was $39.0 \%$, which is higher than the national rate and could be due to being Imam Khomeini Hospital as a tertiary care center in Khuzestan province.

Multiple studies have identified lower GA and BW, higher number of days of oxygen therapy, mechanical ventilation, hyperglycemia, sepsis, blood transfusion, inadequate weight gain during the first 2 weeks, and IVH as risk factors for ROP, with low GA and BW being the most consistent risk factors [18]. Likewise, GA and BW had strong positive correlations with ROP in the current study. Associated risk factors in infants with ROP in order of frequency were oxygen therapy, respiratory distress, phototherapy, blood transfusion, apnea, mechanical ventilation, and IVH. Low GA and BW were independent predictors of ROP.

Karkhaneh et al. [19] screened 185 infants with a BW $\leq 2,500 \mathrm{~g}$ and/or GA $\leq 37$ weeks at the Farabi Hospital in Tehran, Iran. They observed ROP in $20.5 \%$ of neonates with a BW $<1,500$ grams and $26.2 \%$ of neonates with a BW $<1,250$ grams, while the BW was $<2,000 \mathrm{~g}$ in all infants with ROP. Similarly, none of our infants with ROP had BW $>2,000$ grams, and $52.5 \%$ had a BW $<1,200$ grams. They found a significant relationship between the incidence of ROP and blood transfusion, respiratory distress syndrome, and phototherapy. However, there was no significant relationship with oxygen consumption. In their study, ROP was observed in premature infants weighing $<1,000 \mathrm{~g}$ [19]. We found that low GA and BW were independent predictors of ROP. Fouladinejad et al. [20] demonstrated that the use of oxygen therapy was a risk factor for ROP; this was recorded in $22.8 \%$ of premature infants with ROP in the present study and was the most frequent among the listed risk factors.

Basiri et al. [21] screened 80 infants with GA $<34$ weeks, of which $24(30 \%)$ infants had ROP and those with ROP had BW $\leq 1,500 \mathrm{~g}$. There were statistically significant relationships of ROP with GA, BW, need for resuscitation, use of inotropic drugs, 1- and 5-min Apgar scores, and duration of oxygen therapy [21]. In the present study, the frequency of ROP was higher than that in the study by Basir et al. (39.0\% versus $30 \%$ ). However, we also observed ROP mostly $(90.5 \%)$ in infants with $\mathrm{BW} \leq 1,500 \mathrm{~g}$, and oxygen therapy was also the most frequently associated risk factor, seen in 72 (22.8\%) infants of our cohort. Similar to the current study, 
mean GA and BW in infants with ROP were significantly less in infants with ROP than in those without ROP [21], and low GA and BW had significant correlations with ROP [21].

Ahmadpour-kacho et al. [22] found that, of 256 hospitalized premature infants, 180 (70\%) developed some degree of ROP. The mean GA and BW in infants with ROP were significantly lower in infants with ROP than in those without ROP [22], consistent with the present study. The sex distribution was similar to that in our study ( $50 \%$ versus $52.9 \%$ girls). However, compared to their results, the incidence of ROP in the present study was lower (39\%).

Daraie et al. [23] screened 270 premature infants with a BW $\leq 2,000 \mathrm{~g}$ and/or GA $\leq 37$ weeks, of which $55.2 \%$ were boys, which was higher compared to the current study (47\%). Only $2.6 \%$ of infants with ROP had received high levels of oxygen therapy in their study, while in the current study, $22.8 \%$ of infants with ROP had received oxygen therapy. None of the infants with $\mathrm{BW}>1,500 \mathrm{~g}$ in their study developed ROP [23]; similarly, > $90 \%$ of infants in our study had a BW $\leq 1,500 \mathrm{~g}$. The relationship of BW and oxygen therapy with the incidence of ROP was significant but that with sex and GA was not significant in their study [23]. Our study found significantly lower BW and GA in infants with ROP than in those without ROP, and no significant difference in sex distribution was detected.

In a study involving 108 premature infants with a $\mathrm{BW}<2,000 \mathrm{~g}$ or $\mathrm{GA}<36$ weeks, Yang et al. [24] found an ROP incidence rate of $25 \%$ and concluded that low BW and GA were risk factors for the development of ROP. Infants with ROP had a significantly lower mean BW $(1,267 \pm 341 \mathrm{~g})$ and GA $(29.7 \pm 2.7$ weeks $)$ than those without ROP $(1,703 \pm 368 \mathrm{~g}$ and $32.3 \pm 2.2$ weeks $)$. Detected risk factors for ROP were artificial ventilation for over 5 days, chronic lung disease, periventricular leukomalacia, respiratory distress syndrome, IVH, congenital heart disease, and sepsis [24]. Similarly, ROP had a significantly strong correlation with low GA and BW in the current study, and the magnitude of correlation increased with decreasing GA or BW. Multivariate regression analyses showed that low GA and BW were independent predictors of ROP.

Alpay et al. [25] screened 330 infants with a BW $\leq 34$ weeks who were admitted to the NICU, of which $52.4 \%$ were boys, which was higher compared to the current study (47\%). ROP was detected in $32.1 \%$ of infants, consistent with our results (39\%). Type I ROP accounted for $5.4 \%$ of screened infants in their cohort and $17.5 \%$ of screened infants in our study. Similarly, mean GA and BW were significantly lower in infants with ROP, and oxygen therapy was the most common associated risk factor. Type 1 ROP was detected in $11.3 \%$ and $1.1 \%$ of infants with a $\mathrm{BW} \leq 1,500$ and $>1,500$ grams, respectively [25]. This was lower compared to our study, in which type 1 ROP was detected in $19 \%$ of infants with a BW $\leq 1,500 \mathrm{~g}$ and in $10 \%$ of infants with a BW $>1,500 \mathrm{~g}$.

We reported the frequency of ROP and its associated risk factors in Khuzestan, the southern province of Iran, over a 7-year period. ROP is a common cause of preventable blindness in childhood worldwide. Therefore, the results could be helpful in delaying or diminishing the burden of this disease. Regarding risk factors for ROP, Azimi et al. [18] reported use of continuous positive-pressure ventilation, septicemia, oxygen saturation $>50 \%$, and a 1-min Apgar score with an odds ratio (95\% confidence interval) of 3.97 (1.21-13.01), 1.96 (1.10-3.48), 8.35 (3.14-22.18), and 1.07 (0.45-1.68), respectively. Nevertheless, preeclampsia significantly decreased ROP prevalence with an odds ratio (95\% confidence interval) of $0.12(0.02-0.65)$ [18]. However, our study failed to address these factors. As this study was a hospital-based study; the results may not represent the real prevalence of ROP in our region. Future studies are warranted to address these limitations. Moreover, the launch of telemedicine is a breakthrough that facilitates communication between disadvantaged areas and vitreoretinal surgery fellows and should be considered in less-privileged regions, such as the Khuzestan province. Thus, screening for ROP can be improved.

\section{CONCLUSIONS}

This study included all infants with a BW $\leq 2,500 \mathrm{~g}$ and/or $\mathrm{GA} \leq 35$ weeks, who were referred from hospitals throughout Khuzestan province to Imam Khomeini Referral Hospital in Ahvaz, Iran, for ROP screening. The frequency of ROP was 39\%, which was slightly higher compared to previous studies. Most cases were type II ROP, and $>90 \%$ had a BW $<1,500 \mathrm{~g}$. Low BW and young GA were independent predictors of ROP.

\section{ETHICAL DECLARATIONS}

Ethical approval: The study received approval from the research committee of AJUMS (approval code: IR.AJUMS.HGOLESTAN.REC.1398.028).

Conflict of interest: None. 


\section{FUNIDING}

None.

\section{ACIKNOWLEDGEMENTS}

This paper is derived from the medical doctoral thesis of Niusha Kasiri. The authors thank the Deputy of Research and Technology Affairs and Ophthalmology Department of AJUMS. Furthermore, we acknowledge Dr. Ali Kasiri as a supervisor of this research, and declare his paternal relationship with Niusha Kasiri and Rozhin Kasiri, with all having made valid co-author contributions based on International Committee of Medical Journal Editors authorship criteria.

\section{REFERENCES}

1. Yau GS, Lee JW, Tam VT, Liu CC, Yip S, Cheng E, et. al. Incidence and Risk Factors of Retinopathy of Prematurity From 2 Neonatal Intensive Care Units in a Hong Kong Chinese Population. Asia Pac J Ophthalmol (Phila). 2016;5(3):185-91. doi: 10.1097/APO.0000000000000167 pmid: 27183289

2. Kola M, Hacioğlu D, Erdöl H, Türk A, Aslan Y. Determination of regional screening criteria for retinopathy ofprematurity in the Eastern Black Sea region of Turkey. Turk J Med Sci. 2016;46(2):381-7. doi: 10.3906/sag-1410-97 pmid: 27511500

3. Zarei M, Bazvand F, Ebrahimiadib N, Roohipoor R, Karkhaneh R, Farahani Dastjani A, et. al. Prevalence and Risk Factors of Retinopathy of Prematurity in Iran.J Ophthalmic Vis Res. 2019;14(3):291-298. doi: 10.18502/jovr.v14i3.4785 pmid: 31660108

4. Hong EH, Shin YU, Cho H. Retinopathy of prematurity: a review of epidemiology and current treatment strategies. Clin Exp Pediatr. 2021. doi: 10.3345/cep.2021.00773 pmid: 34645255

5. Mostafa Gharehbaghi M, Peirovifar A, Sadeghi K. Plasma leptin concentrations in preterm infants with retinopathy of prematurity (ROP). Iranian Journal of Neonatology. 2012; 1(3):12-6. doi: 10.22038/IJN.2012.275

6. Mustafa Gharebaghi M, Sadegh K, Zarghami N, Mostafizi H. Serum vascular endothelial growth factor-1 (VEGF-1), leptin and insulin-like growth factor measurement in retinopathy of prematurity. Stud Med Sci. 2012; 23(2): 183-90. [Persian] Link

7. Naderian G, Iranpour R, Mohammadizadeh M, Najafabadi FF, Badiei Z, Naseri F, et al. The frequency of retinopathy of prematurity in premature infants referred to an ophthalmology clinic in Isfahan.J Isfahan Med Sch. 2011;29(128):1-5. [Persian] Link

8. Nakhshab M, Ahmadzadeh Amiri A, Dargahi S, Farhadi R, Yazdani J. The incidence rate of retinopathy of prematurity and related risk factors: a study on premature neonates hospitalized in two hospitals in sari, Iran, 2014-2015. J Kerman Univ Med Sci. 2016;23(3):296-307. [Persian]Link

9. Heidary F, Gharebaghi R. Outcomes of Retinopathy of Prematurity. Med Hypothesis Discov Innov Ophthalmol. 2016;5(4):112-114. pmid: 28293657

10. Edy Siswanto J, Sauer PJ. Retinopathy of prematurity in Indonesia: Incidence and risk factors. J Neonatal Perinatal Med. 2017;10(1):85-90. doi: 10.3233/NPM-915142 pmid: 28304327

11. Gebeşçe A, Uslu H, Keleş E, Yildirim A, Gürler B, Yazgan H, et. al. Retinopathy of prematurity: incidence, risk factors, and evaluation of screening criteria. Turk J Med Sci. 2016;46(2):315-20. doi: 10.3906/sag-1407-127 pmid: 27511491

12. Senthil MP, Salowi MA, Bujang MA, Kueh A, Siew CM, Sumugam K, et. al. Risk Factors and Prediction Models for Retinopathy of Prematurity. Malays J Med Sci. 2015;22(5):57-63 pmid: 28239269

13. Fajolu IB, Rotimi-Samuel A, Aribaba OT, Musa KO, Akinsola FB, Ezeaka VC, et. al. Retinopathy of prematurity and associated factors in Lagos, Nigeria. Paediatr Int Child Health. 2015;35(4):324-8. doi: 10.1080/20469047.2015.1109277 pmid: 26744157

14. Alajbegovic-Halimic J, Zvizdic D, Alimanovic-Halilovic E, Dodik I, Duvnjak S. Risk Factors for Retinopathy of Prematurity in Premature Born Children. Med Arch. 2015;69(6):409-13. doi: 10.5455/medarh.2015.69.409-413 pmid: 26843736

15. Mgharbil E, Raffa LH, Alessa S, Alamri A. Screening premature infants for retinopathy of prematurity in a tertiary hospital in Saudi Arabia. Ann Saudi Med. 2020;40(2):87-93. doi: 10.5144/0256-4947.2020.87 pmid: 32241163

16. Chiang MF, Quinn GE, Fielder AR, Ostmo SR, Paul Chan RV, Berrocal A, et. al. International Classification of Retinopathy of Prematurity, Third Edition. Ophthalmology. 2021;128(10):e51-e68. doi: 10.1016/j.ophtha.2021.05.031 pmid: 34247850

17. Good WV; Early Treatment for Retinopathy of Prematurity Cooperative Group. The Early Treatment for Retinopathy Of Prematurity Study: structural findings at age 2 years. Br J Ophthalmol. 2006;90(11):1378-82. doi: 10.1136/bjo.2006.098582 pmid: 16914473

18. Azami M, Jaafari Z, Rahmati S, Farahani AD, Badfar G. Prevalence and risk factors of retinopathy of prematurity in Iran: a systematic review and meta-analysis. BMC Ophthalmol. 2018;18(1):83. doi: 10.1186/s12886-018-0732-3 pmid: 29606108

19. Karkhaneh R, Riazi Esfahani M, Ghojehzadeh L, Kadivar M, Nayeri F, Chams H, et. al. Incidence and risk factors of retinopathy of prematurity. Bina J Ophthalmol. 2005;11(1):81-90. [Persian] Link

20. Fouladinejad M, Motahari MM, Gharib MH, Sheishari F, Soltani MO. The prevalence, intensity and some risk factors of retinopathy of premature newborns in Taleghani Hospital, Gorgan, Iran.J Gorgan Univ Med Sci. 2009;11(2). [Persian]Link

21. Basiri B, Sabzehei MK, Shokouhi Solgi M, Akbarzadeh S, Ivazeh S. Frequency and risk factors of retinopathy of prematurity in newborns admitted to neonatal intensive care unit in Hamadan. Avicenna J Clin Med. 2019; 26(1): 44-50. doi: 10.29252/ajcm.26.1.44

22. Ahmadpour-kacho M, Pasha YZ, Rasoulinejad SA, Hajiahmadi M, Pourdad P. Correlation between retinopathy of prematurity and clinical risk index for babies score. Tehran Univ Med J. 2014;72(6). [Persian] Link

23. Daraie G, Nooripoor S, Ashrafi AM, Ghorbani R. Incidence of retinopathy of prematurity and some related factors in premature infants born at Amir-al-Momenin hospital in Semnan, Iran. Koomesh. 2016; 17(2):297-303. [Persian] Link

24. Yang CS, Chen SJ, Lee FL, Hsu WM, Liu JH. Retinopathy of prematurity: screening, incidence and risk factors analysis. Zhonghua Yi Xue Za Zhi (Taipei). 2001;64(12):706-12. pmid: 11922490

25. Alpay A, Uğurbaş SH. Incidence and risk factors for retinopathy of prematurity in the West Black Sea region, Turkey. TurkJ Pediatr. 2012;54(2):113-8. pmid: 22734296 